\title{
Role of full length weight bearing radiograph in assessing the Alignment in Total Knee Arthroplasty
}

\author{
Sukumaran Subbiah Subramanian ${ }^{1}$, Mugundhan MoongilpattiSengodan ${ }^{2}$ \\ ${ }^{1}$ (Orthopedics, Chengalpattu medical college, India.) \\ ${ }^{2}$ (Orthopedics, Coimbatore medical college, India.)
}

\begin{abstract}
Various factors contribute to the decrease in the longevity of the total knee arthroplasty. Of these various factor, mal-alignment of the components and hence the axial alignment of limb is well within the control of the operating surgeon. The aim of the study is to compare the axial alignment of the lower extremity before and after surgery in patients undergoing total knee replacement by assessing the mechanical axis in the full length weight bearing radiograph taken preoperatively and post operatively. And to correlate the midterm results with reference to the mechanical axis. While in all the patients in the study group showed a statistically significant improvement between the preoperative and postoperative knee scores, the unfavorable group did not show any significant improvement in the knee scores. In midterm follow up we conclude that a strong correlation exists between the functional outcome and the axial alignment of the extremity postoperatively. And hence full length weight bearing radiograph is a valuable tool in determining the mechanical axis.
\end{abstract}

Keywords: Full length radiograph, total knee arthroplasty, alignment, mechanical axis

\section{Introduction}

The surgeon performing a total knee arthroplasty is not only concerned with the early pain relief to the arthritic patient but should also provide the patient with stable functional knee with the maximum implant survival. Survivorship for cemented total knee arthroplasty ranges between $91 \%$ and $99 \%$ at ten years andbetween $91 \%$ and $96 \%$ at 15 years [1\&2]. Various factors contribute to the decrease in the longevity of the implants which may be patient specific, material specific, design specific, surgeon specific and biologic specific.

Of these various factor, mal-alignment of the components and hence the axial alignment of limb is well within the control of the operating surgeon. Several studies have concluded that durability of the total knee replacement is dependent on the postoperative axial alignment of the lower extremity [3-8]. If replacement of the knee leaves the extremity in varus or valgus mal-alignment, loosening and instability occurs at a greater rate than if the limb is well aligned by arthroplasty. Mal-alignment leads to overload of the bone and ligaments, leading to asymmetric bone loss, prosthetic wear and fracture and ligamentous instability.

Preoperative axial alignment of the lower extremity is essential to assess the bony cuts to be taken during surgery as well as the ligamentous balancing to be performed intra operatively. Hence assessment of axial alignment before and after surgery is imperative in any patient undergoing a knee replacement surgery. Best method of assessing axial alignment is to assess the mechanical axis of the lower extremity in the coronal plane. The normal standing radiograph which provides a view of the knee only, is prone to errors of parallax and poor control of patient positioning [9]. Weight bearing full length radiograph of the lower limb including the hip, knee and ankle is essential for the accurate assessment of mechanical axis and hence the axial alignment of the lower extremity.

\section{Aim}

The aim of the study is to compare the axial alignment of the lower extremity before and after surgery in patients undergoing total knee replacement by assessing the mechanical axis in the full length weight bearing radiograph taken preoperatively and post operatively. And to correlate the midterm results with reference to the mechanical axis.

\section{Literature Review}

The concept of the weight bearing or "mechanical" axis was described by Pauwels in his classic work "Biomechanics of the locomotor apparatus" published in 1980 [10]. He has described mechanical axis as a static weight bearing axis which can be drawn on a radiographic image of the limb.Earlier in 1972, Maquet has described the axial alignment of the lower limb and the mechanical axis is some time described as "Maquet Line"[11].

Various studies published in different periods have proved that a strong relationship exists between the post-operative mechanical axis and the long term survival of the implants [3-6]. In a bone model study conducted in Department of Orthopedic Surgery, Harvard Medical School, Boston in 1989, Hsu et al have concluded that misalignment by 5 degrees yielded a $40 \%$ change in the load distribution; a 10 degrees 
misalignment produced changes of $62 \%$ [12]. Malalignment increased the rate of revision in many studies [13$15]$.

\subsection{Mechanical axis}

The mechanical axis of the lower limb in the frontal plane is defined as a line drawn from the center of the femoral head to the center of the ankle joint. This line is also called as Maquet's line [11]. It normally passes through the center of the knee joint in the frontal plane, described as 'neutral mechanical axes.

The distance of this line from the center of the knee on a long-leg radiograph provides the most accurate measure of coronal alignment.Mal alignment causes abnormal forces which may lead to loosening after knee replacement. During normal gait the mechanical axis is inclined 3 degrees from the vertical axis of the body, with feet closer to the midline than the hips. When the mechanical axis lies to the lateral side of the knee center, the knee is in mechanical valgus alignment. In mechanical varus alignment, the axis lies to the medial side of the knee center.

\subsubsection{Femoral axes}

Each long bone has a mechanical axis and an anatomic axis [16-19].In the femur the anatomical and mechanical axes are not parallel. They converge distally. The mechanical axis of femur runs from the center of femoral head to center of knee. The anatomical axis of the femurintersects the knee joint line medial to the knee joint center in the vicinity of medial tibial spine. When extended proximally it usually passes through the piriform fossa just medial to the greater trochanter medial cortex.

\subsubsection{Physiologic valgus angle (Alpha angle)}

The anatomical axis of femur is in 6 to 8 degrees of valgus from the mechanical axis of lower limb and 9 to 11 degrees of valgus from the true vertical axis of the body. This angle which is formed between the anatomical and mechanical axes of the femur is the physiological valgus angle or the alpha angle. This angle has an important bearing in the distal cut of the femur during the intra operative procedure. It decides the angle at which the intra-medullary alignment rod is to be fixed to the femoral cutting block.

\subsection{Alignment radiograph}

\subsubsection{Cassette frame}

Three 14" X 17" cassettes are stacked together and mounted on a wooden frame [20]. Two metal markers usually $4.5 \mathrm{mmX} 150 \mathrm{~mm}$ Shanz pins are pasted at the junction of the metal edges of the cassettes in a vertical direction. Third Shanz of similar dimension is placed in the middle of the center cassette

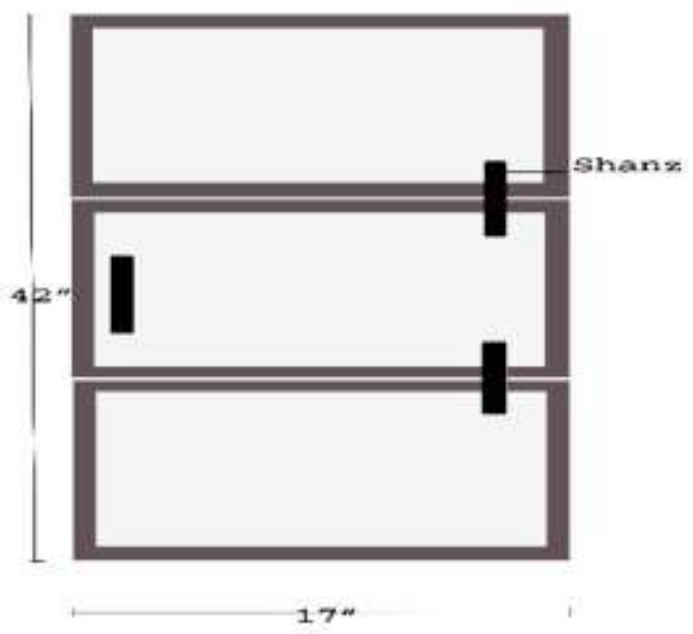

Total height of the cassette is 42 inches and the width is 17 inches.

\subsubsection{Patient Positioning}

Patient is made to stand in front of wooden frame mounted with the cassette. He or she is instructed to bear weight on both feet equally. For standing radiographs, the radiography technologists are usually taught to position the patient with the feet together. But if the patient has external or internal tibial torsion, such positioning will result in the patella pointing inward or outward. This will result in wrong interpretation of mechanical axes [21]. 
The correct method is to orient the patella forward, irrespective of the foot position. To orient the patella forward, the patella is felt with the index finger and the thumb of one hand and rotated forward till it points forward. The radiograph confirms the correct position, showing the patella centered between femoral condyles [20].
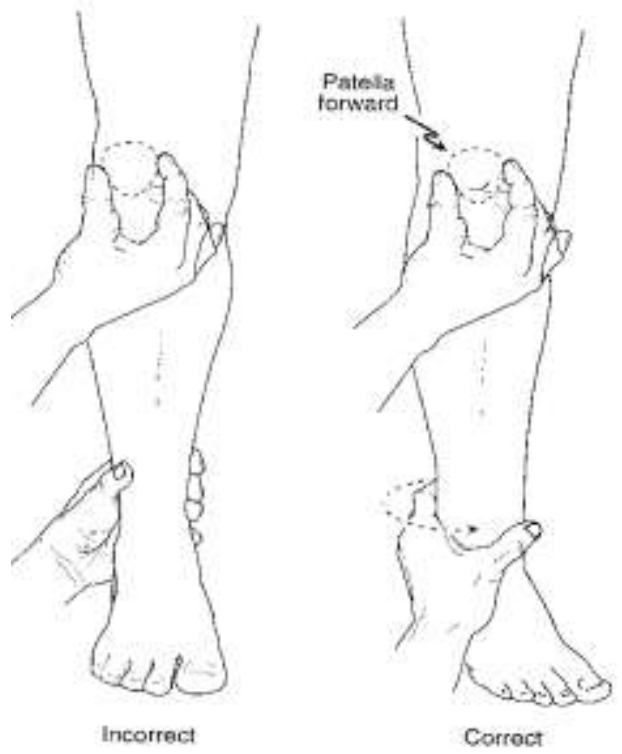

The plane of the knee flexion extension axis is approximately 3 degrees externally rotated to the frontal plane. However a difference less than 5 degrees does not alter the joint orientation lines significantly. Wright et al intheir experiment on the impact of rotation on alignment radiograph have stated that 20 degree of either rotation produced only a small overall effect on the alignment radiograph [21].

Therefore whether the radiograph is obtained in the true frontal plane or perpendicular the knee flexion axis, the angles measured will be approximately the same.

\subsubsection{Exposure}

Theradiograph is taken by digital X-ray. The X-ray source is placed at a distance of 6 feet from the patient. The beam is centered on the knee joint of the patient. The patient is asked to bear weight equally on both the legs. Any rotation if present is corrected. A $100 \mathrm{~mA}, 0.05$ second exposure is used at 100 to $115 \mathrm{kV}$, ending on the leg thickness. The approximate magnification by this method is $10 \%-20 \%$.

\subsubsection{Digitization of radiographs}

Captured image is transferred to a computer and the image is processed in the Scandock image software. Correct magnification factor is assessed using the Shanz pin placed in the center of central cassette. With the magnification factor thus obtained, the image from the three cassettes are stitched and aligned using the two Shanz pin placed across the junction of the cassettes.

Finally the mechanical axis of the lower extremity, anatomical and mechanical axes of the femur as well as the tibia are made. The tibial plateau is divided into seven zones and the zone through which the mechanical axis passes is determined. Final print out is made from the computer in a 14"to17" $\mathrm{x}$-ray film.Physiological valgus angle was also measured.

\subsubsection{Tibial Zones}

Next the tibial plateau was divided into seven zones namely $0,1,2, \mathrm{C}, 3,4,5$ where $\mathrm{C}$ represents the central zone [5].

Zone 0: Medial to the medial end of medial tibial plateau

Zone 1: Medial half of medial tibial plateau

Zone 2: Lateral half of medial tibial plateau

Zone C: Between tibial spine

Zone 3: Medial half of lateral tibial plateau

Zone 4: Lateral half of lateral tibial plateau

Zone 5: Lateral to the lateral end of lateral tibial plateau 


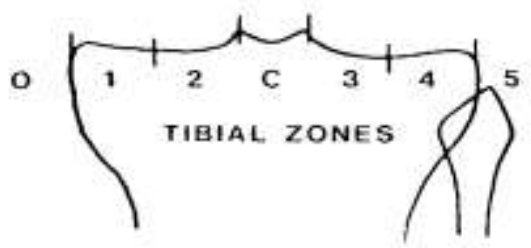

The zone of the knee through which the mechanical axis of the limb passed was then recorded. This recording was made in preoperative as well as postoperative full length radiograph and results analyzed.

\section{Materials}

In Kilpak medical college hospital, Chennai total knee arthroplasty is being done for various indications. The period of study is from June 2004 and May 2006. During the study period 43 knees were replaced in 35 patients. All patients who underwent total knee arthroplasty in our hospital during the period of June 2004 to May 2006 with regular follow-up up to 10 years were included in this study.

The patients who did not turn for follow-up up to eight years were excluded from the study. We have also excluded patients in whom there was preoperative fixed flexion deformity of the knee of more than 20 degrees, coexisting arthritis of hip, postoperative infection, periprosthetic fracture or any other fracture in the lower limbs during the follow up period of eight years. Hence the study involved 25 patients with 30 knees.

The data were collected from all the patients as per the proforma like age, sex, height and weight there by body mass index, side of the knee to be operated and the etiology of arthritis whether rheumatoid or primary osteoarthritis [Table 1].

Table 1. Master chart

\begin{tabular}{|c|c|c|c|c|c|c|c|c|c|c|c|c|c|c|c|c|c|c|}
\hline No & $\begin{array}{l}\text { ag } \\
\text { e }\end{array}$ & $\begin{array}{l}\mathbf{S} \\
\mathbf{e} \\
\mathbf{x}\end{array}$ & $\begin{array}{l}\text { Heig } \\
\text { ht } \\
\text { (cm) }\end{array}$ & $\begin{array}{l}\text { Wt } \\
(K \\
\text { g) }\end{array}$ & BMI & $\begin{array}{l}\text { Indi } \\
\text { cati } \\
\text { on }\end{array}$ & $\begin{array}{l}\mathbf{S} \\
\mathbf{i} \\
\mathrm{d} \\
\mathrm{e}\end{array}$ & $\begin{array}{l}\text { Defor } \\
\text { mity }\end{array}$ & $\begin{array}{l}\text { K } \\
\text { L } \\
\text { Sc } \\
\text { or } \\
\text { e }\end{array}$ & $\begin{array}{l}\text { Val } \\
\text { gus } \\
\text { Ang } \\
\text { le } \\
\text { (de } \\
\text { gre } \\
\text { es) }\end{array}$ & $\begin{array}{l}\text { Pr } \\
\text { eo } \\
\text { p } \\
\text { Zo } \\
\text { ne }\end{array}$ & $\begin{array}{l}\text { Po } \\
\text { sto } \\
\text { p } \\
\text { Zo } \\
\text { ne }\end{array}$ & $\begin{array}{l}\text { Pre } \\
\text { op } \\
\text { KS }\end{array}$ & $\begin{array}{l}\text { Po } \\
\text { sto } \\
\text { p } \\
\text { KS }\end{array}$ & $\begin{array}{l}10 \\
\text { yea } \\
\text { rs } \\
\text { foll } \\
\text { ow } \\
\text { up } \\
\text { KS }\end{array}$ & $\begin{array}{l}\text { Pre } \\
\text { op } \\
\text { FS }\end{array}$ & $\begin{array}{l}\text { Po } \\
\text { sto } \\
\text { p } \\
\text { FS }\end{array}$ & $\begin{array}{l}10 \\
\text { yea } \\
\text { rs } \\
\text { Foll } \\
\text { ow } \\
\text { up } \\
\text { FS }\end{array}$ \\
\hline 1 & 47 & $\mathrm{~F}$ & 154 & 48 & 20.25 & RA & $\mathrm{R}$ & Valgus & 4 & 6 & 4 & $\mathrm{C}$ & 38 & 85 & 84 & 47 & 72 & 76 \\
\hline 2 & 47 & $\mathrm{~F}$ & 154 & 48 & 20.25 & RA & $\mathrm{L}$ & Varus & 3 & 7 & 2 & $\mathrm{C}$ & 42 & 89 & 89 & 47 & 72 & 76 \\
\hline 3 & 62 & $\mathrm{~F}$ & 157 & 80 & 32.52 & $\mathrm{OA}$ & $\mathrm{L}$ & Varus & 4 & 7 & 0 & 1 & 54 & 47 & 0 & 58 & 50 & 0 \\
\hline 4 & 42 & $\mathrm{~F}$ & 158 & 55 & 22.08 & RA & $\mathrm{R}$ & Valgus & 3 & 7 & 4 & 1 & 48 & 64 & 59 & 52 & 72 & 72 \\
\hline 5 & 42 & $\mathrm{~F}$ & 158 & 55 & 22.08 & RA & $\mathrm{L}$ & Valgus & 3 & 7 & 3 & 2 & 50 & 86 & 84 & 52 & 72 & 72 \\
\hline 6 & 65 & $\mathrm{~F}$ & 153 & 61 & 26.06 & $\mathrm{OA}$ & $\mathrm{R}$ & Varus & 4 & 7 & 0 & 2 & 45 & 83 & 81 & 48 & 80 & 80 \\
\hline 7 & 62 & M & 162 & 65 & 24.8 & $\mathrm{OA}$ & $\mathrm{R}$ & Varus & 4 & 8 & 0 & 2 & 41 & 95 & 96 & 50 & 86 & 85 \\
\hline 8 & 66 & $\mathrm{~F}$ & 150 & 64 & 28.44 & $\mathrm{OA}$ & $\mathrm{R}$ & Varus & 4 & 7 & 0 & $\mathrm{C}$ & 55 & 92 & 93 & 54 & 78 & 80 \\
\hline 9 & 66 & $\mathrm{~F}$ & 150 & 64 & 28.44 & $\mathrm{OA}$ & $\mathrm{L}$ & Varus & 4 & 7 & 0 & 2 & 53 & 90 & 90 & 54 & 78 & 80 \\
\hline 10 & 58 & $\mathrm{M}$ & 165 & 63 & 23.16 & $\mathrm{OA}$ & $\mathrm{R}$ & Varus & 4 & 7 & 0 & $\mathrm{C}$ & 41 & 92 & 90 & 48 & 86 & 89 \\
\hline 11 & 58 & $\mathrm{M}$ & 165 & 63 & 23.16 & $\mathrm{OA}$ & $\mathrm{L}$ & Varus & 4 & 7 & 0 & $\mathrm{C}$ & 40 & 91 & 92 & 48 & 86 & 89 \\
\hline 12 & 76 & $\mathrm{~F}$ & 150 & 55 & 24.44 & $\mathrm{RA}$ & $\mathrm{R}$ & Valgus & 2 & 7 & 3 & $\mathrm{C}$ & 53 & 78 & 76 & 57 & 71 & 75 \\
\hline 13 & 62 & $\mathrm{~F}$ & 154 & 54 & 22.78 & $\mathrm{OA}$ & $\mathrm{R}$ & Varus & 2 & 7 & 1 & 2 & 50 & 88 & 84 & 52 & 86 & 88 \\
\hline 14 & 62 & $\mathrm{~F}$ & 154 & 54 & 22.78 & $\mathrm{OA}$ & $\mathrm{L}$ & Varus & 3 & 7 & 2 & $\mathrm{C}$ & 45 & 92 & 91 & 52 & 86 & 88 \\
\hline 15 & 63 & $\mathrm{~F}$ & 154 & 52 & 21.94 & $\mathrm{OA}$ & $\mathrm{L}$ & Valgus & 4 & 7 & 4 & 2 & 42 & 84 & 81 & 44 & 76 & 75 \\
\hline 16 & 54 & $\mathrm{~F}$ & 154 & 49 & 20.66 & RA & $\mathrm{R}$ & Varus & 4 & 7 & 1 & $\mathrm{C}$ & 39 & 86 & 85 & 48 & 73 & 70 \\
\hline 17 & 64 & $\mathrm{~F}$ & 152 & 50 & 21.64 & $\mathrm{OA}$ & $\mathrm{R}$ & Varus & 4 & 7 & 2 & 2 & 43 & 90 & 88 & 51 & 73 & 78 \\
\hline 18 & 56 & $\mathrm{~F}$ & 155 & 76 & 31.63 & $\mathrm{OA}$ & $\mathrm{L}$ & Varus & 2 & 7 & 2 & $\mathrm{C}$ & 46 & 93 & 91 & 49 & 87 & 89 \\
\hline 19 & 59 & $\mathrm{~F}$ & 152 & 65 & 28.13 & $\mathrm{OA}$ & $\mathrm{R}$ & Varus & 4 & 7 & 0 & 1 & 47 & 75 & 68 & 50 & 65 & 54 \\
\hline 20 & 49 & $\mathrm{~F}$ & 158 & 53 & 21.23 & $\mathrm{OA}$ & $\mathrm{L}$ & Valgus & 3 & 7 & 3 & 2 & 51 & 87 & 84 & 53 & 76 & 77 \\
\hline 21 & 65 & $\mathrm{~F}$ & 153 & 60 & 25.63 & $\mathrm{OA}$ & $\mathrm{R}$ & Varus & 3 & 6 & 0 & 2 & 46 & 84 & 83 & 49 & 81 & 79 \\
\hline 22 & 63 & $\mathrm{M}$ & 151 & 63 & 27.63 & $\mathrm{OA}$ & $\mathrm{L}$ & Varus & 4 & 7 & 2 & $\mathrm{C}$ & 42 & 96 & 92 & 51 & 87 & 88 \\
\hline 23 & 66 & $\mathrm{~F}$ & 150 & 65 & 28.88 & $\mathrm{OA}$ & $\mathrm{L}$ & Varus & 4 & 7 & 0 & $\mathrm{C}$ & 56 & 93 & 90 & 55 & 79 & 78 \\
\hline 24 & 69 & $\mathrm{~F}$ & 153 & 66 & 28.19 & $\mathrm{OA}$ & $\mathrm{R}$ & Varus & 3 & 7 & 1 & 1 & 52 & 48 & 41 & 59 & 52 & 43 \\
\hline 25 & 58 & $M$ & 166 & 61 & 22.13 & $\mathrm{OA}$ & $\mathrm{L}$ & Varus & 4 & 7 & 0 & $\mathrm{C}$ & 40 & 91 & 87 & 47 & 85 & 85 \\
\hline 26 & 76 & $\mathrm{~F}$ & 150 & 52 & 23.11 & RA & $\mathrm{R}$ & Varus & 4 & 8 & 0 & $\mathrm{C}$ & 52 & 77 & 76 & 56 & 70 & 69 \\
\hline 27 & 65 & $\mathrm{~F}$ & 154 & 55 & 23.19 & $\mathrm{OA}$ & $\mathrm{R}$ & Varus & 2 & 7 & 2 & $\mathrm{C}$ & 49 & 87 & 87 & 51 & 85 & 82 \\
\hline 28 & 58 & M & 162 & 66 & 25.14 & $\mathrm{OA}$ & $\mathrm{R}$ & Varus & 4 & 7 & 0 & 2 & 39 & 91 & 90 & 47 & 85 & 86 \\
\hline 29 & 63 & $\mathrm{~F}$ & 161 & 51 & 19.67 & $\mathrm{OA}$ & $\mathrm{R}$ & Valgus & 3 & 7 & 4 & 2 & 41 & 83 & 84 & 43 & 75 & 79 \\
\hline 30 & 61 & $\mathrm{~F}$ & 157 & 54 & 21.9 & $\mathrm{OA}$ & $\mathrm{L}$ & Varus & 2 & 7 & 2 & $\mathrm{C}$ & 44 & 91 & 92 & 47 & 85 & 90 \\
\hline
\end{tabular}


Scoring system formulated by the American Knee Society is used to evaluate the patients before and after surgery. Both knee scores and functional scores are calculated with each amounting to a total of 100 points [23].Preoperative full length radiograph was taken in all the patients who underwent knee replacement surgery. Radiological grading system as advocated by Kellegren and Lawrence was used to evaluate the severity of the arthritis and graded from I to IV [24].

The physiologic valgus angle determined after marking the mechanical and anatomical axes of the femur. Joint center of the hip knee and ankle were marked. Mechanical axis of the limb to be operated was marked. Deviation from the center of the knee joint center was calculated by dividing the tibial plateau into seven zones and determining the zone through which the axis passed [Figure 1].

Surgeries were performed by different surgeons at various period of time during the study period. Pneumatic tourniquet was routinely used in all cases. PCL was sacrificed in all the cases and ultra-congruent tibial inserts were used. The cemented standard tibial component is used for the tibia (Endoplus Inc.).

Standard postoperative protocol as advised by the American Knee society was followed. Patients were discharged after suture removal on the tenth post-operative day.

Postoperative full length radiograph was taken during the first review, four weeks after surgery; the mechanical axis as well the deviation of the mechanical axis was determined as before and values compared with the preoperative measurements and the results analyzed [Figure 2]. At ten years follow up clinical examination with knee society scoring was done.

Data from the study analyzed by simple linear regression and results critically reviewed.

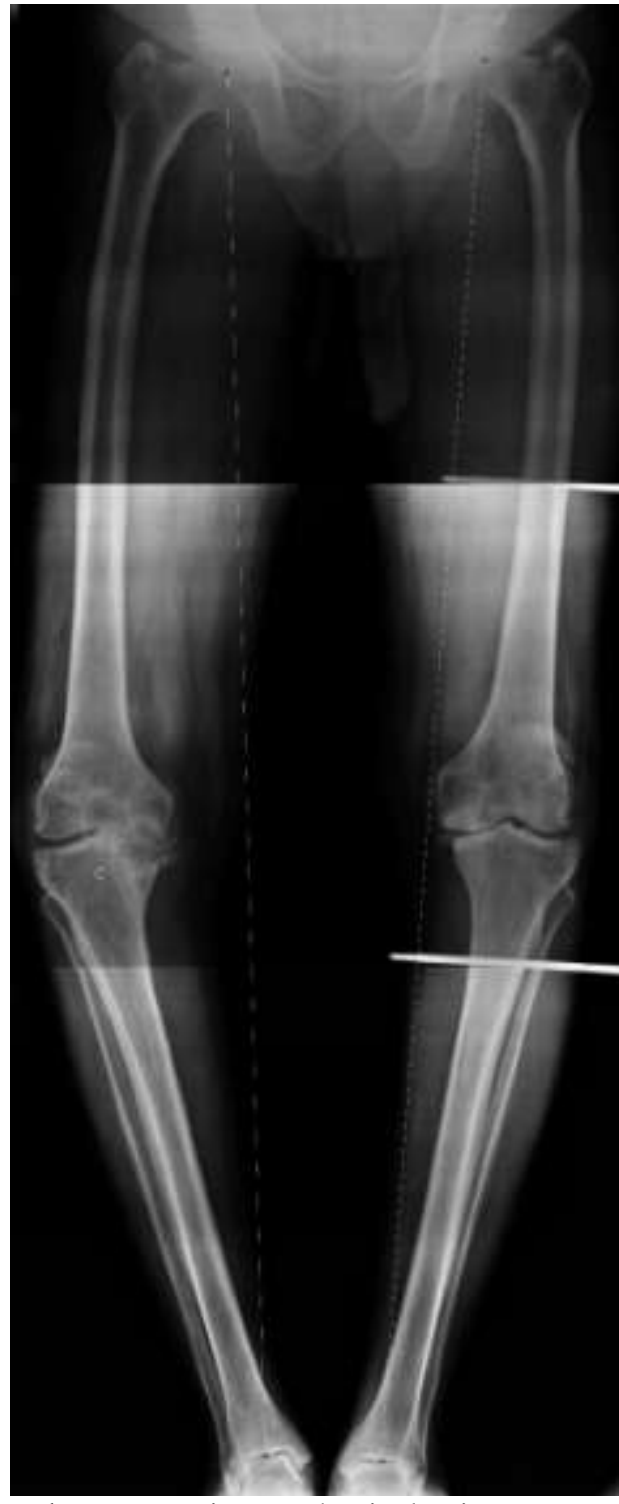

Figure 1. Preoperative mechanical axis

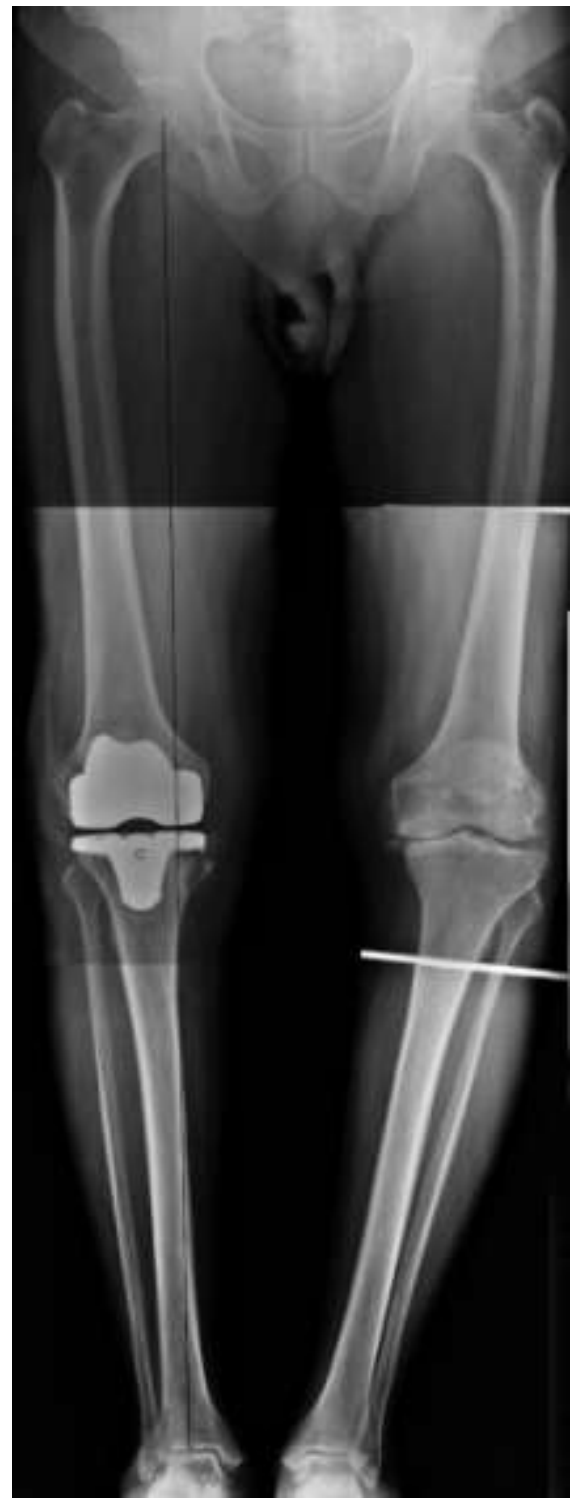

Figure 2. Postoperative mechanical axis 


\section{V. results}

The age of the patients who underwent total knee replacement in our series ranged from 42 to 76 years with a mean of 60.13 years. The standard deviation was 8.33 and $80 \%$ of our patient belonged to the sixth and seventh decade. Two third of our patients were within the normal range of the BMI. Mean was 24.40 and SD was 3.44 .

\subsection{KSS Score}

All the patients were evaluated by scoring system proposed by The American Knee Society. The average preoperative knee score was 46.13 with the range of 38 to 56 and SD of 5.44 It improved by 38.14 to an average of 84.27 postoperatively, the SD being 12.01. The mean knee score at ten years follow up was 80.93 with SD being 18.91 .

The mean preoperative functional score was 50.63 ( $\mathrm{SD}=3.94$ ). It improved post operatively by a margin of 26.34 with a mean of $76.97(\mathrm{SD}=9.49)$. The mean functional score at ten years follow up was 75.73 $(\mathrm{SD}=17.59)$

The severity of the arthritis was assessed with the Kellegren and Lawrence scoring system which revealed that nearly $60 \%(\mathrm{no}=17)$ of our patient had grade IV arthritis at presentation.

\subsection{Valgus angle}

The physiological valgus angle was measured in all our patients using the preoperative full length radiograph. This angle is significant in that it decides the perpendicularity of the femoral cut to the mechanical axis of femur. $86.67 \%$ of our patients had a valgus angle (alpha angle) of 7 degrees.

\subsection{Mechanical axis}

Before surgery mechanical axis passed through the middle third of the knee in none of our patients whereas after surgery in $50 \%$ of the cases $(n=15)$ the mechanical axis passed through the center of the knee (Zone $\mathrm{C})$ and in $36.67 \%(\mathrm{n}=11)$ it passed through the zone 2 . The high number of results with a mechanical axis that passed through zone 2 or zone $\mathrm{C}$ indicates the natural tendency of the surgeon to position the knee in a neutral or slightly valgus alignment.

It was also observed in our study that failure to achieve postoperative axial alignment occurred in one valgus knee and in three varus knees which accounts for about $13.33 \%$ of cases. In those 4 cases the mechanical axis was in zone 1 post operatively. One of the 4 cases underwent revision after 6 years following the index surgery due to aseptic loosening. The remaining three cases had significantly low knee scores and radiological evidence of aseptic loosening at ten years follow up.

\section{Data Analysis}

Results were analyzed by simple linear regression analysis in Microsoft excel. The tibial zone in which the mechanical passed through as the variable(x), postoperative knee score and functional score showed significant difference when it passed away from the central zone $(\mathrm{p}<0.005)$ [Table 2].

Table 2. Simple linear regression analysis with postoperative scores

\begin{tabular}{|l|l|l|l|l|l|l|}
\hline \hline \multicolumn{2}{|l|}{ Regression Statistics } & & & & & \\
\hline \multicolumn{2}{|l|}{} & & & & & \\
\hline (y= postoperative K score) & & & & & & \\
\hline \\
\hline Intercept & Coefficients & Standard Error & t Stat & P-value & Lower 95\% & Upper 95\% \\
\hline X Variable & 55.4035 & 5.4096 & 10.2416 & $5.67 \mathrm{E}-11$ & 44.3224 & 66.4846 \\
\hline & 12.0263 & 2.1609 & 5.56524 & $5.93 \mathrm{E}-06$ & 7.59977 & 16.4528 \\
\hline & & & & & & \\
\hline
\end{tabular}

Similarly, with the tibial zone in which the mechanical passed through as the variable(x), postoperative knee score and functional score at ten years follow up also showed significant difference when it passed away from the central zone $(\mathrm{p}<0.005)$ [Table 3$]$. 
Role of full length weight bearing radiograph in assessing the Alignment in Total Knee Arthroplasty

Table 3. Simple linear regression analysis with ten years follow up scores

\begin{tabular}{|l|l|l|l|l|l|l|}
\hline \hline $\mathrm{y}=$ ten years Follow up K score $)$ & & & & & & \\
\hline & Coefficients & Standard Error & t Stat & P-value & Lower 95\% & Upper 95\% \\
\hline Intercept & 38.0175 & 9.00698 & 4.2208 & 0.000232 & 19.5675 & 56.4675 \\
\hline $\mathrm{X}$ Variable 1 & 17.8815 & 3.59800 & 4.9698 & $3.01 \mathrm{E}-05$ & 10.5114 & 25.2517 \\
\hline \hline$(\mathrm{y}=$ ten years follow up F score) & & & & & & \\
\hline & Coefficients & Standard Error & $t$ Stat & P-value & Lower 95\% & Upper 95\% \\
\hline Intercept & 39.2280 & 8.9640 & 4.3761 & 0.000152 & 20.8661 & 57.59 \\
\hline $\mathrm{X}$ Variable 1 & 15.2105 & 3.5808 & 4.2477 & 0.000216 & 7.87552 & 22.5455 \\
\hline
\end{tabular}

\section{Discussion}

Total knee arthroplasty for arthritic patients in whom all the conservative measures are exhausted, is an excellent procedure if proper attention is paid to the patient selection. Meticulous surgical technique must be performed to attain satisfactory postoperative alignment. Good functional results are obtained by correctly positioned implants. Proper positioning of the implants is assessed by the central alignment of the mechanical axis [25]. Long radiographs including hip, knee and ankle (three joint $\mathrm{x}$-ray) are essential to study the axial alignments. Short radiographs and short arm goniometers are accurate only to 5 degrees. When the patient is carefully positioned and the knees are in full extension and the patient is bearing weight in both knees, full length standing radiographs can be used to measure the angles to within 2 degrees. Measuring this angle to 5 degree accuracy would not appear to be sufficiently precise to detect the moderate degree of mal-alignment which can affect the result [22].

The rotation of the lower extremity will affect the apparent alignment that is seen when the radiograph is made [26]. If the knee is flexed a little, external rotation will make knee appear to be in more varus angulation, and internal rotation will accentuate the degree of valgus angulation. Thus the radiograph should be made with the patella pointing straight ahead, assuming that the patella is not subluxated or dislocated. If the tibial or femoral component is in a mal rotated position, determination of the axial alignment of the lower extremity becomes more complex [22].Hence long length radiograph after proper positioning of the patients is a valuable tool in assessing the mechanical axis of the extremity.

Long radiographs are not only essential for accurate assessment of the axial alignment of the lower limb but also necessary for estimating the 'physiological valgus angle'. The angle at which the cutting block should be fixed to the intra-medullary alignment rod is determined by the preoperatively measured valgus angle in the full length radiograph. Thus it is imperative to assess the valgus angle in every patients undergoing knee replacement. In our study, this measurement ranged from 6 to 8 degrees with the mode being 7 degrees.

In addition, post-operative full length alignment $\mathrm{x}$-ray taken after every case helps in the self-assessment of the surgeon regarding the restoration of mechanical axis and thus helps to reduce the learning curve of the individual surgeon and improves the surgical precision.

Gbejuade $\mathrm{HO}$ et al stated that in the malaligned limb, weight-bearing full length X-ray still remains a vital imaging modality [27]. When compared to weight-bearing full length $\mathrm{X}$ ray, supine Computerized Tomographic scanogram should be used with caution in view of the under-detection of malalignment [27-30].

Using Kettelkamp and Chao's[31] work as reference, when the mechanical axis passed through zone 0 or zone 1 the medial compartment is loaded with $100 \%$ of the weight bearing forces. Only when the femero tibial angle was 0 degrees or a valgus angle did the lateral compartment begin to bear weight [32]. Loading in zone 0 and zone 1 should be avoided because Zone 0 and zone 1 alignment excessively load the medial compartment and increases the possibility of eventual failure. Zone 2 and zone $C$ results load the knee more normally and their results were uniformly superior to other zone results. With alignment in zone 2 or zone $\mathrm{C}$ the kinematics of the joint more closely approaches that of normal knee.

With alignment zone 3, results are slightly inferior in that they load the lateral compartment and result in more cases of lateral compartment wear than zone 2 or zone C. Zone 4 should be avoided because it indicates that excessive medial release has occurred at the time of ligament balancing and will result in instability. None of our cases are zone 3 or zone 4 aligned. Thus under correction (zones1 or zone 0 ) will result in excessive loading of the medial compartment and increased tendency for loosening of the components. Over correction (zone 3, 4 and 5) will result in an increased incidence of lateral wear and instability. None of our cases was overcorrected.

William R Kennedy et al in their 51 month follow-up of one hundred consecutive cases conclude that the alignment and position of the component affects the outcome of the procedure by controlling the medial lateral weight distribution [5]. Although the initial postoperative results with a poorly aligned knee may be satisfactory, the long-term results will be affected by the overall alignment. It has been observed by various authors that zone 2 and zone $\mathrm{C}$ postoperative alignment seems to improve patellar alignment also [5]. In our study, the midterm review showed the similar results. 
As the knee is aligned in increasing varus, the patella tracks with an increasing load on the medial patellar facet. By observing during surgery the frequency of medial patello femoral cartilage changes in varus knee, it appears that subsequent redirection of patellar forces to lateral patellofemoral cartilage in patient with zone 2 or zone $\mathrm{C}$ resultant, mechanical axis would be favorable.

Jeffery et al found that out of 6070 primary total knee arthroplasty there were 51 prosthesis failures, 21 $(0.5 \%)$ in the neutral cohort, $18(1.8 \%)$ varus, and $12(1.5 \%)$ valgus group. They reported that when the axis passed through the middle one-third of the prosthesis, this resulted in a $3 \%$ rate of loosening. Moreover, when the axis was shifted either medial or lateral, the loosening rate was noted to be much higher ( $24 \% P=0.001$ ) [33].

In four of our knees the axis passed through the unfavorable zone 1 . This includes three varus knees. In one of the valgus knees, though the axis had shifted from the most unfavorable zone 0 , it is still passes through zone 1, which is less unfavorable. In our series linear regression analyses showed inferior results with zone 1 when compared to zone $\mathrm{C}$ or zone 0 . This is on par with the data available from the literature[13, $32 \& 33]$.

\section{Conclusion}

While in all the patients in the study group showed a statistically significant improvement between the preoperative and postoperative knee scores, the unfavorable group did not show any significant improvement in the knee scores. This was reflected in our ten years follow up also. Thus a strong correlation exists between the functional outcome and the axial alignment of the extremity postoperatively.

We conclude that valgus angle must be assessed in individual patients by taking full length radiographs pre-operatively to get axial alignment corrected. Post-operative study of mechanical axis in full length weight bearing $\mathrm{x}$-ray is very useful to assess the restoration of mechanical axis back to normal. Further long term studies with larger number of cases are needed to establish this correlation.

\section{References}

[1]. 1. Scuderi Gr, Insall JN, Windsor RE, Moran MC. Survivorship of cemented knee replacements J Bone Joint Surg Br. 1989;71B 798-803

[2]. 2. Ritter MA, Herbst SA, Keating EM, FarisPM.Meding JB. Long term survival analysis of posterior cruciate retaining total condylar knee arthroplasty. ClinOrthop. 1994;309:136-145

[3]. Lotke, PA and Ecker ML: Influence of Positioning of Prosthesis in Total Knee Replacement, J Bone Joint Surg59-A: 77-79, Jan 1977

[4]. Weinstein JN, Andriacchi TP, Galante J: Factors influencing walking and stair climbing following unicompartmental knee arthroplasty, J Arthroplasty 1986; 1(2):109-15

[5]. Kennedy WR, White RP:Unicompartmental arthroplasty of the knee. Postoperative alignment and its influence on overall results, ClinOrthopRelat Res 1987 Aug ;( 221):278-85

[6]. Jonsson B, Astrom J. Alignment and long-term clinical results of a semi constrained knee prosthesis, ClinOrthopRelat Res (226):124-8. Jan 1988.

[7]. Ritter MA, Faris PM, Keating EM, Meding JB. Postoperative alignment of total knee replacement. Its effect on survival.ClinOrthopRelat Res.1994 Feb ;(299):153-6.

[8]. Hernigou P, Deschamps G. Alignment influences wear in the knee after medial unicompartmental arthroplasty. ClinOrthop 2004; (423): 161-5.

[9]. Siu D, Cooke TD, Broekhoven LD, Lam M, Fisher B, Saunders G, Challis TW. A standardized technique for lower limb radiography. Practice, applications, and error analysis. Invest Radiol. 1991 Jan; 26(1):71-7.

[10]. Pauwels F: Biomechanics of the locomotor apparatus, New York, Springer Verlag, 1980.

[11]. Maquet P: Biomecanique de la gonarthrose, Ada OrthopBelg38(Suppl I): S33-S54, 1972.

[12]. Hsu HP, Garg A, Walker PS, Spector M, Ewald FC:Effect of knee component alignment on tibial load distribution with clinical correlation. ClinOrthopRelat Res (248):135-44: Nov 1989.

[13]. Robert S. Jeffery, Richard W. Morris, Robin A. Denham: Coronal alignment after total knee replacement; J Bone Joint Surg [Br] 1991; 73-8:709-14.

[14]. Ritter MA, Faris PM, Keating EM, Meding JB: Postoperative alignment of total knee replacement. Its effect on survival ClinOrthopRelat Res (299):153-6: Feb 1994

[15]. Kolstad K, Sahlstedt B, Bergstrom R. Marmor modular knee plateau positioning and prosthesis survival in 55 knees with rheumatoid arthritis. Arch Orthop Trauma Surg 115(1):17-21: 1996.

[16]. Chao EYS, Neluheni E V D, Hsu RWW, Paley D. Biomechanics of mal-alignment. OrthClin N.A. 25: 379 386, 1994.

[17]. Krackow KA. Approaches to planning lower extremity alignment for total knee arthroplasty and osteotomy about the knee. Advances in OrthSurg 7; 68 88. 1983.

[18]. Paley D, Tetsworth K. Mal-alignment and realignment of the lower extremity. OrthClin N. A.Vol 25, 367 555, July 1994.

[19]. Paley D, Tetsworth K. Mechanical axis deviation of the lower limbs; Preoperative planning of multi apical frontal pane angular deformities of the femur and tibia. Clin. Orthop 280: 65 71, 1992.

[20]. Paley D, Principles of Deformity Correction, Springe-Verlag, Berlin Heidelberg 2002

[21]. Wright JG, Treble N, Feinstein AR (1991) Measurement of lower limb alignment using long radiographs. J Bone Joint Surg Br. 73: $721-723$

[22]. Moreland JR, Bassett LW, Hanker GJ. Radiographic analysis of the axial alignment of the lower extremity. J Bone Joint Surg 69A: $745749,1987$.

[23]. John N. Insall, Lawrence D. Dorr, Richard D. Scott, and W. Norman Scott: Rationale of the Knee Society Clinical Rating System. ClinOrthop. 1989 Nov; (248):13-14.

[24]. Kellgren JH, Lawrence JS. Radiological assessment of osteo-arthrosis. Ann Rheum Dis 1957; 16: $494-502$. 
[25]. Cook TDV, Scudamore RA, Bryant JT, Sorbie C, Siu D, Fisher B: A Quantitative approach to radiography of the lower limb. Principles and applications J Bone Joint Surg Br.1991; 73-B: 715-20

[26]. Lonner J H, Laird M T, Stuchin S A. Effect of rotation and knee flexion on radiographic alignment in total knee arthroplasty. ClinOrthop 1996; (331): 102-6.

[27]. 27.Gbejuade HO, White $\mathrm{P}$, Hassaballa $\mathrm{M}$ et al Do long leg supine $\mathrm{CT}$ scanograms correlate with weight-bearing full-length radiographs to measure lower limb coronal alignment? Knee 2014 Mar; 21(2):549-52.

[28]. Thomas J Holme, Johann Henckel, Kai Hartshorn, et al Computed tomography scanogram compared to long leg radiograph for determining axial knee alignment. ActaOrthop. 2015 Aug; 86(4): 440-443.

[29]. Babazadeh S, Dowsey M, Bingham R et al. The long leg radiograph is a reliable method of assessing alignment when compared to computer assisted navigation and computer tomography. Knee. 2013; 20(4):242-9.

[30]. ChristineM. Shearman1, Eric A. Brandser1, MaryH. Kathol1 et al. An Easy Linear Estimation of the Mechanical Axis on Long-Leg Radiographs. AJR 1998; 170:1220-1222.

[31]. Kettelcamp DB, Chao EY, A method of quantitative analysis of medial and lateral compression forces at the knee during standing. Clin. Orthop. 83:202, 1972.

[32]. Hsu RWW, Himeno S, Coventry MB, Chao EYS. Normal axial alignment of the lower extremity and load bearing distribution at the knee. Clin. Orthop. Rel. Research. 255: 215 227, 1990.

[33]. Jeffrey J. Cherian, Bhaveen H. Kapadia, Samik Banerjee et al. Mechanical, Anatomical, and Kinematic Axis in TKA: Concepts and Practical Applications. Curr Rev Musculoskelet Med. 2014 Jun; 7(2): 89-95. 